\title{
Erratum to: Increased and early lipolysis in children with long-chain 3-hydroxyacyl-CoA dehydrogenase (LCHAD) deficiency during fast
}

\author{
C. Bieneck Haglind • A. Nordenström • S. Ask • \\ U. von Döbeln • J. Gustafsson • M. Halldin Stenlid
}

Published online: 21 November 2014

(C) SSIEM 2014

\section{Erratum to: J Inherit Metab Dis}

DOI 10.1007/s10545-014-9750-3

In the Results section, plasma and subcutaneous glycerol should be measured in micromolar $(\mu \mathrm{M})$ and not in millimolar $(\mathrm{mM})$. The mistake occurred 8 times. The passage should read as follows:

Levels of plasma glycerol (mean $72 \pm 32 \mu \mathrm{M}$, min $18 \mu \mathrm{M}$, $\max 143 \mu \mathrm{M})$ (Fig. 2c) and glycerol in subcutaneous adipose tissue (mean 304 $\pm 96 \mu \mathrm{M}, \min 83 \mu \mathrm{M}, \max 530 \mu \mathrm{M}$ ) (Fig. 2a) increased after 3-4 h, while there were no changes in levels of NEFA and TAG. The mean levels of microdialysis glycerol were $59 \%$ higher during the fasting-night, compared to the corresponding time period the previous night, on normal diet including night feeds (mean $304 \pm 96 \mu \mathrm{M}$ compared to $191 \pm$ $64 \mu \mathrm{M})$.

The online version of the original article can be found at http://dx.doi.org/ 10.1007/s10545-014-9750-3.

C. B. Haglind $(\bowtie) \cdot$ A. Nordenström

Women's and Children's Health, Karolinska Institute, Stockholm,

Sweden

e-mail: charlotte.haglind@ki.se

U. von Döbeln

Division of Metabolic Diseases, Department of Laboratory

Medicine, Karolinska Institute, Stockholm, Sweden

S. Ask

Astrid Lindgren Children's Hospital, Karolinska University Hospital,

Stockholm, Sweden

J. Gustafsson • M. H. Stenlid

Department of Women's and Children's Health, University

Children's Hospital, Uppsala, Sweden 